\title{
Keruncong Stambul Fajar Dalam Acara Selamat Laut Di Pulau Mendanau Kabupaten Belitung
}

\author{
Irwansyah $^{1}$
}

\begin{abstract}
Mendanau Island is one of the islands located in Belitung archipelago. People in Mendanau island mostly work as fishermen. The fishermen community in Mendanau island, precisely in the village of Suak Gual, held a ceremony once a year called Selamat Laut. This ceremony was held in several days by performing traditional art performance, one of them is Keruncong Stambul Fajar(KSF) music. KSF music consists of several instruments namely three ukulele, one viul / violin, one acoustic guitar, and a bass guitar. KSF music is played at the completion of the Selamat Laut ceremony during a shared meal called Bedulang. This study aims to reveal the form of presentation, function and reason of KSF music taking part in the ceremony. The ethnomusicological approach is used as the main approach in this study, with the help of other sciences such as anthropology, sociology and linguistics. The research was conducted by field observation and literature review.

The Selamat Laut ceremony is a form of expression of the request for salvation and a request to be kept away from the bad things that may happen while sailing, which in the implementation is led by a village shaman followed by all fishing communities in the village of Suak Gual. KSF music itself was involved in the ceremony as the performers after the Selamat Laut ceremony to accompany the people enjoying the meal, that presented as musical and pantun performances using traditional clothes on the stage. The KSF Group of Pengekar Campo presenting two songs called KSF Semol and KSF Dua Mol, with a musical form of 20 bars for KSF Semol and 18 bars for KSF Dua Mol. Music KSF has two functions i.e. primary and secondary function. The primary functions included the function as a means of entertainment, and as an aesthetic presentation. Secondary functions included the function as solidarity enchancher and as a communication medium. Through the function of the KSF music make it as music that always involved in various events, that KSF music can be said as the identity of the Mendanau island community.
\end{abstract}

Keywords: Selamat Laut Ceremony, Musical Performance, Keruncong Stambul Fajar.

\footnotetext{
${ }^{1}$ Mahasiswa jurusan Etnomusikologi FSP ISI Yogyakarta; email: arsyah2312@gmail.com
} 


\begin{abstract}
Abstrak
Pulau Mendanau ialah salah satu pulau yang terdapat di kepulauan Belitung. Masyarakat yang tinggal di pulau Mendanau sebagaian besar berprofesi sebagai nelayan. Masyarakat nelayan di pulau Mendanau tepatnya di desa Suak Gual setiap setahun sekali selalu melaksanakan sebuah upacara Selamat Laut. Upacara Selamat Laut dilaksanakan beberapa hari dengan menampilkan kesenian tradisional salah satunya ialah musik Keruncong Stambul Fajar (KSF). musik KSF terdiri dari beberapa instrumen yaitu tiga ukulele, satu viul/biola, satu gitar akustik, dan gitar bas. Musik KSF dimainkan pada waktu selesainya upacara Selamat Laut saat acara makan Bedulang atau makan bersama. Penelitian ini bertujuan untuk mengungkap bentuk penyajian, fungsi dan mengapa musik KSF yang dimainkan dalam upacara tersebut. Pendekatan etnomusikologis dipergunakan sebagai pendekatan utama dalam penelitian ini, dengan dibantu ilmu lain seperti antropologi, sosiologi dan lingustik. Penelitian dilakukan dengan pengamatan lapangan dan kajian kepustakaan.

Upacara Selamat Laut adalah sebuah bentuk ungkapan permohonan keselamatan dan permintaan untuk dijauhkan dari hal-hal buruk yang dapat terjadi saat pergi melaut, dalam pelaksanaannya dipimpin oleh dukun kampung dengan diikuti oleh seluruh masyarakat nelayan yang ada di desa Suak Gual. Musik KSF sendiri dilibatkan dalam upacara tersebut sebagai pengisi acara setelah upacara Selamat Laut untuk mengiringi masyarakat menikmati hidangan makanan, disajikan di atas panggung dengan menggunakan pakaian adat serta menyajiakan pertunjukan musik dan pantun. Grup KSF Pengekar Campo membawakan dua buah lagu yaitu KSF Semol dan KSF Dua Mol dengan bentuk musik 20 birama untuk KSF Semol dan 18 birama untuk KSF Dua Mol. Musik KSF memiliki dua fungsi yaitu fungsi primer dan fungsi sekunder. Fungsi primer meliputi fungsi sebagai sarana hiburan, dan fungsi sebagai presentasi estetis. Fungsi sekunder meliputi fungsi sebagai peningkat solidaritas dan fungsi sebagai media komunikasi. Melalui fungsi dari musik KSF menjadikanya sebagai musik yang selalu dilibatkan dalam berbagai acara, dapat dikatakan musik KSF merupakan identitas dari masyarakat pulau Mendanau.
\end{abstract}

Kata Kunci : Upacara Selamat Laut, Pertunjukan Musik, Keruncong Stambul Fajar. 


\section{Pendahuluan}

Pulau Mendanau adalah salah satu pulau terbesar di kepulauan Belitung dan dikelilingi pulau-pulau kecil. Pulau Mendanau terbagi atas tiga desa yaitu desa Selat Nasik, desa Petaling, dan desa Suak Gual sebagai bagian kecamatan Selat Nasik kabupaten Belitung.

Mayoritas masyarakatnya memeluk agama Islam. Islam masuk sekitar abad ke-17 dibawa oleh seorang ulama yang berasal dari Pasai (Aceh) bernama Syaid Abubakar alias Syekh Abdullah (Husnail Husin Abdullah, 1983: 209). Cerita tentang Syekh Abdullah dikenal dengan sebutan Keramat Gunong Tajam.

Masyarakat pulau Mendanau mayoritas juga berkerja sebagai nelayan, sehingga banyak aktifitas masyarakat dilakukan berhubungan dengan laut. Salah satunya ialah sebuah upacara Selamat Laut. Upacara ini merupakan aktifitas tahunan yang dilaksanakan setiap memulai musim angin barat, awal bulan November pada awal musim penghujan yang terkadang menggangu aktifitas mencari ikan yang dilakukan masyarakat pulau Mendanau sehingga upacara Selamat Laut dilaksanakan untuk menolak hal-hal buruk yang dapat terjadi saat pergi melaut.

Upacara Selamat Laut (seperti namanya) merupakan upacara yang mengharapkan keselamatan selama melaut atau sebagai penolak dari hal-hal buruk. Upacara ini dipimpin langsung oleh dukun kampung dan biasanya masyarakat nelayan akan membawa peryaratan upacara yaituTepung Tawar yang terbuat dari beras yang telah ditumbuk halus, serta daun Temiang Berani dan daun Tangga Emas.

Dahulu upacara Selamat Laut hanya dilaksanakan secara sederhana tanpa sebuah perayaan.Seiring berkembangnya masyarakat serta kemajuan pembangunan, kini upacara Selamat Laut sengaja dikemas sedemikian rupa layaknya sebuh perayan besar yang dilaksanakan berhari-hari serta melibatkan beberapa kesenian tradisional untuk menghibur,salah satunya musik Keruncong.

Keruncong merupakan sebuah kesenian musik yang berkembang dalam lingkungan masyarakat Pulau Mendanau. Seperti dalam upacara pernikahan musik Keruncong dimainkan sebagai hiburan pada malam hari saat menjaga 
makanan agar tidak diganggu oleh hewan, selama menjaga makanan tersebut musik Keruncong terus dimainkan bersamaan dengan menikmati makanan atau disebut dengan tambul yang berarti kue yang dihidangkan (http://kbbi.web.id/tambul. Diakses 2 Agustus 2017), disediakan untuk orang yang sedang bermain musik Keruncong hingga pagi hari. Sehingga musik Keruncong ini disebut masyarakat pulau Mendanau dengan sebutan Keruncong Stambul Fajar. Istilah kata Keruncong sendiri secara analogi sama halnya dengan Keroncong hanya saja mengalami perubahan karena dialek masyarakat lokal pulau Mendanau yang mayoritas masyarakatnya Melayu Belitung.

Musik Keroncong berasal dari Kata Keroncong yang berasal dari bunyi yang ditimbulkan oleh instrumen gitar kecil yang berasal dari Polynesia (ukulele) (Harmunah, 1987: 9). Sejarah yang cukup panjang sebelum tahun 1852 telah terjadi kontak budaya antara masyarakat pulau Belitung dengan bangsa Eropa seperti Belanda, Inggris dan Portugis. Berhubungan dengan salah satu genre musik yang berkembang di daerah Belitung, terjadinya kontak budaya tersebut bukan tidak mungkin menginspirasi masyarakat lokal. Akulturasi budaya Barat dengan budaya lokal telah melahirkan salah satu dari jenis irama Keroncong. Kemudian salah satu instrumen musik Keroncong yang dikenal di daerah Belitung dan dimainkan oleh masyarakat yakni ukulele dan seniman lokal menyebutnya istrumen keruncong (Wawancara dengan Suherman Jabing pada tanggal 3 Juli 2017). Istrumen musik ukulele inilah kemudian lahir genre musik yang dikenal di Belitung dengan sebutan Keruncong Stambul Fajar.

Musik Keruncong Stambul Fajar terdapat di pulau Mendanau yang dimainkan oleh dua grup, yaitu grup Keruncong Stambul Fajar Sedap Malam dan grup Keruncong Stambul Fajar Pengekar Campo, dalam penelitian ini penulis menjadikan grup Keruncong Stambul Fajar Pengekar Campo sebagai objek penelitian karena pertimbangan dari kondisi grup yang dilihat dari keaktifan latihan, eksistensi, kondisi instrumen, masih adanya penerus atau regenerasi dari musik Keruncong dan adanya perhatian lebih dari pemerintah daerah seperti pengadaan instrumen dan bantuan pengeras suara. 
Grup KSF Pengekar Campo yang terdapat di desa Suak Gual mereka memainkan musik KSF ini dengan menggunakan beberapa instrumen yaitu tiga gitar ukulele berdawai 4 (nilon), biola (viul) berdawai 4 (baja), gitar akustik dan terakhir gitar Bas akustik.

Lagu-lagu yang dimainkan dalam musik ini menggunakan syair pantun yang dinyayikan oleh perempuan dan laki-laki. Musik KSF ini memiliki dua judul lagu yang disebut Semol (satu mol) dan Dua Mol (Wawancara dengan Suherman Jabing pada tanggal 3 Juli 2017). Sesuai dengan tempat berkembang dan hidupnya musik KSF sudah tentu tidak lepas dari nuansa Melayu dan budaya masyarakat lokal yang ada dalam irama musik Keruncong Stambul Fajar.

\section{Pelaksanaan Upacara Selamat Laut}

Persiapan sebelum upacara dilakukan dengan pembentukan panitia, perencanaan anggaran serta penentuan hari pelaksanaan, persiapan dilakukan tiga bulan sebelum acara, melalui musyawarah desa di kantor desa Suak Gual yang dihadiri oleh dukun kampung, lembaga adat dan masyarakat desa Suak Gual, hasil dari musyawarah terbentuklah kepanitiaan.

Rencana anggaran dan penetapan hari pelaksanaan upacara yaitu acara dilaksanakan selama lima hari dari tanggal 22 sampai 26 November 2017 yaitu hari pertama pembukaan, hari kedua Meluber (Melukis Bersama) dan Begaple, hari ketiga kreasi seni anak-anak, hari keempat lumbe de tepitemparan (perlombaan di pinggir pantai) dan parade seni budaya dan hari kelima bekeria'ankemudian acara puncak ialah ritual selamat laut.

Pelaksanaan upacara Selamat Laut pada tanggal 26 November 2017 dimulai pagi hari pada pukul 08.30 WIB dengan mempersiapkan segala perlengkapan dan persyaratan upacara yaitu tepung tawar yang terdapat dalam baskom, daun temiang berani dan daun tangga emas yang dimasukan dalam botol yang berisi air putih. Perlengkapan dibawa oleh seluruh masyarakat nelayan kemudian dikumpulkan di atas panggung kecil yang telah disiapkan sebelumnya.

Selanjutnya proses penyambutan bupati pukul 13.30 WIB dari pintu masuk jalan pelabuhan dengan dipikul oleh empat orang laki-laki menggunakan 
kursi juli kemudian diarak dengan permainan musik hadroh bersamaan dengan para rombongan yang datang menuju bangsalan untuk duduk bersama dengan masyarakat nelayan sambil menunggu pelaksanaan upacara.

Proses acara inti pacara Selamat Laut acara inti dimulai sekitar pukul 13.45 WIB dengan dipandu oleh pembawa acara atau MC yang diawali sambutan dari kepala desa dan diteruskan oleh Bupati Belitung. Selanjutnya upacara diserahkan sepenuhnya kepada dukun kampung yang memimpin upacara dengan membacakan ayat-ayat pendek seperti surat Al Fatihah, surat Al-Ikhlas, surat AlFalaq dan surat An Nas. Ketiga surat pendek ini dibacakan berulang-ulang oleh dukun kampung dengan suara cukup keras, selain pembacaan surat pendek, juga dibacakan beberapa doa secara pribadi oleh sang dukun, dilain pihak masyarakat peserta upacara juga ikut berdoa dalam hati, dengan kedua belah tangan terbuka.

Selanjutnya setelah proses pembacaan doa telah selesai, dukun kampung beserta ketua adat menuju perahu nelayan untuk melakukan proses ngerimbas yaitu memukulkan atau memercikkan air dari tepung tawar yang telah diberi doa dengan menggunakan daun temiang berani dan tangga emas pada perahu nelayan sebanyak tiga kali pada bagian depan perahu, ngerimbas dimulai pertama kali oleh dukun kampung kemudian diikuti oleh bupati, kepala desa berserta tokoh adat, setelah selesai selanjutnya ngerimbas dilanjutkan oleh pemilik perahu untuk ngerimbas pada bagian dalam dan belakang perahu sebanyak tiga kali. Setelah itu proses upacara Selamat Laut selesai, kemudian seluruh masyarakat nelayan diminta untuk mengambil tepung tawar, daun temiang berani, daun tangga emas dan botol milik mereka untuk segera digunakan pada perahu mereka kemudian setelah rangkaian upacara Selamat Laut, masyarakat selama tiga hari dilarang untuk pergi melaut.

Setelah proses upacara Selamat Laut selesai dilanjutkan dengan acara makan bedulang dalam bahasa Melayu Belitung adalah sebuah sajian makanan yang ditempatkan dalam dulang. Dulang ini sejenis tempat meletakkan makanan yang berbentuk lingkaran biasanya berbahan dasar logam. Makanan yang disajikan berupa makanan tradisional yang telah disiapkan oleh masyarakat 
makanan itu berupa masakan ikan gangan, sayur nangka, lalapan berupa rebus pucuk singkong, sambal terasi, dan sebagai pencuci mulut ada bubur bigi'delime.

Acara makan berdulang ini dinikmati bersama-sama dari para tamu undangan hingga seluruh masyarakat yang hadir dipersilakan untuk makan, begitulah pemandu acara atau MC memberitahukan melalui panggung pertunjukan yang mempersilahkan masyarakat untuk makan, pada saat bersamaan diatas panggung telah dipersiapan pertunjukan musik Keruncong Stambul Fajar.

1) Pra pertunjukan

Persiapan sebelum diadakan pertunjukan musik KSF ialah menyiapkan alat musik yang berada di atas panggung dengan memasang pengeras suara untuk semua alat musik agar mudah didengar oleh para penonton yang pada waktu itu masih peserta dari upacara Selamat Laut. Para pemain dari musik KSF pada waktu itu ada tujuh orang dengan enam orang laki-laki dan satu orang perempuan, kebetulan pada saat pertunjukan itu penulis diberikan kesempatan untuk memainkan salah satu alat musik KSF . Ketujuh orang tersebut ialah (1) Ahmad bin bujang alias Kik Mat, sebagai guru yang mengajarkan musik KSF. Alat musik yang dimainkan gitar akustik, (2)Awal, alat musik yang dimainkan ialah keruncong atau gitar ukulele dengan pola nganak., (3) Deva, alat musik yang dimainkan gitar bas, (4) Irwansyah, alat musik yang dimainkan keruncong atau gitar ukulele dengan pola ngelingka, (5) Santi, ialah sebagai vokal perempuan, (6) Suherman, sebagai pemimpin dari grup KSF Pengekar Campo. Alat yang dimainkan ialah biola atau viul, dan (7) Wawan alias Sepoy, awalnya sebagai pemain gitar ukulele kemudian pada saat acara menjadi vokal laki-laki.

Sebelum acara dimulai telah disiapkan instrumen dari KSF yang sebelumnya telah berada di atas panggung, instrumen yang digunakan pada waktu pertunjukan saat upacara Selamat Laut hanya menggunakan beberapa instrumen (1) Biola (Viul), (2) Gitar akustik, (3) 2 (dua) Ukulele dan gitar Bas.

2) Pelaksanaan Pertunjukan Musik KSF

Sebelum memulai pertunjukan dari musik KSF salah satu pemain dari KSF memperkenalkan tentang grup dan para pemain musik KSF Pengekar Campo, setelah memperkenalkan diri dilanjutkan dengan mengucapkan selamat 
menikmati makanan yang telah disediakan panitia untuk tamu undangan dan masyarakat. Salah satu penyanyi menyebutkan lagu yang akan mereka bawakan lagu pertama ialah lagu dengan irama semol kemudian dilanjutkan dengan irama duamol. Setiap irama lagu terdapat dua pantun, pantun pertama yang dinyanyikan laki-laki kemudian dilanjut dengan pantun kedua oleh perempuan dengan irama semol.

Batang terancap batang teruntum Dalamlah bakau tumbohlah nipa Kamek ucap assallamu'alikum Sebagailah tanda baru berjumpa Wani-wani ukanlah baje Baje pemutong padi de sawah Saya bernyayi ukan sengaje Menghibur hati yang sedang susah
Jika pohon teruntum sudah tertancap Bakau yang rimbun tumbuhlah nipah Assallamu'alikum kami ucapkan Sebagai tanda baru berjumpa Bukan baja sembarang baja Baja pemotong padi di sawah Kebetulan saya menyanyi Hanya untuk menghibur hati yang susah

Sekitar satu sampai dua menit setelah kedua pantun dinyanyikan dengan irama semol selanjutnya penyanyi laki-laki menyampaikan ulang lirik dari lagu dan menjelaskan secara singkat maksud dari lagu tersebut, dilanjutkan dengan menyayikan lagu kedua dengan irama dua mol.

Hendak kepulau kepulaulah

Janganlah sampai bulan purname Hendak bergurau berguraulah

Jangan sampai badan binase Ributlah- ribut berangin-angin Ribut pagi matakan tiang Selagi hidup kita bermain Setelah mati tergolek seorang
Jika ingin pergi kepulau pergilah sekarang Janganlah menunggu berganti bulan Jika ingin bercanda bercandalah sekarang Mumpung kita masih hidup Angin pantai bertiup kencang Pagi hari merobohkan tiang Selagi bersama mari kita bermain Jika mati jenazah tinggal sendiri

Setelah pantun kedua sekitar satu hingga dua menit selanjutnya sama dengan setelah lagu pertama yaitu penyanyi laki-laki menjelaskan ulang lirik dari pada lagu dan menjelaskan secara singkat makna dari lagu tersebut. Kemudian setelah penyampaian makna dari pantun mereka menutup pertunjukan musik 
dengan mengucapkan salam dan pertunjukan kembali dipandu oleh pembawa acara.

\section{Penutup}

Penutup pada saat pertunjukan atau penyajian musik KSF ditutup setelah pantun terakhir yang disampaikan langsung oleh salah satu penyayi, selanjutnya pertunjukan terakhir pada rangkaian acara yaitu pertunjukan tari pada acara Selamat Laut ada dua tarian yang pertama tarian Mantang Karet yang ditarikan anak-anak dan tarian kedua tarian makan Besaji yang ditarikan ibu-ibu. Tarian ini ialah sebagai penutup dalam rangkaian acara Selamat Laut.

Tari Mantang Karet, dengan pakaian busana yang rapi berserta hiasan yang warna warni tarian ini ditarikan dengan sangat ceria, seketika lapangan mulai dipenuhi oleh masyarakat karena ingin menyaksikan tarian tersebut. Setelah penampilan tarian ini maka selesai sudah rangkaian acara Selamat Laut pada tanggal 26 November 2017.

\section{Keruncong Stambul Fajar (KSF)}

Keruncong Stambul Fajar merupakan sebuah musik yang berfungsi sebagai hiburan masyarakat. Kata keruncong terpengaruh dari kebiasaan masyarakat Melayu Belitung dalam berdialek seperti kata "orang” dalam bahasa Indonesia jika disebutkan dalam bahasa Melayu Belitung menjadi "urang”. Maka kata keruncong itu merupakan analogi dari kata keroncong. Sedangkan kata stambul fajar berasal dari kebiasaan masyarakat dalam memainkan musik keruncong yang dimainkan pada waktu hajatan atau upacara tertentu, dimainkan pada malam hari hingga menjelang fajar atau pagi hari, selama musik ini dimainkan akan diberikan tambul berarti kue yang dihidangkan (http://kbbi.web.id/tambul. Diakses 2 Agustus 2017) untuk para pemain musik, kebiasaan memainkan musik ini menjadikan musik keruncong dikenal dengan Keruncong Stambul Fajar, pada pertunjukannya digunakan untuk menunggu makanan yang sebelumnya telah dimasak pada siang hari untuk besok disajikan pada hari hajatan atau upacara. 
Musik keruncong diperkirakan masuk kepulauan Belitung pada tahun 1852, merupakan tahun dibangunnya Billiton Maatschappij sebagai sebuah perusahaan swasta milik para aristokrat Belanda (Erwiza Erman, 2009: 13). Pembangunan perusahaan tambang timah ini, diduga menjadi awal pengaruh masuknya musik keroncong ke wilayah kepulauan Belitung yaitu pulau Mendanau. Salah satu prasasti atau bangunan bersejarah yang dibangun untuk menerangi atau penuntun kapal keluar masuk wilayah perairan pulau Mendanau berupa mercusuar Tanjung Lancor yang dibangun oleh Belanda pada tahun 1883. Disisi lain Mercusuar Tanjung Lancor tersebut dapat dikatakan sebagai saksi bisu pertempuran yang pernah terjadi pada 14 Desember 1945 antara pasukan TKR dengan pasukan NICA (Husnail Husin Abdullah, 1983: 275).

Walaupun sekilias, pemaparan historis tersebut dapat dipakai sebagai bukti masuknya budaya Barat yang beradaptasi dengan budaya lokal, dan salah satu bentuk kesenian tersebut adalah KSF (Keruncong Stambul Fajar). Pengaruh tersebut berasal dari instrumen ukulele yang ada pada musik keroncong asli pada krontjong toegoe di daerah Cilincing Jakarta Utara hanya saja secara jumlah pada musik KSF menggunakan tiga ukulele yang terpengaruh dari budaya lokal sehingga penggunaan ukulele menjadi tiga, lagu yang dimainkan musik KSF berbeda dengan lagu keroncong pada umumnya, KSF memiliki dua lagu yang penamaannya sama dalam istilah musik yaitu kata Semol dan Kata Dua Mol istilah ini dalam musik mengartikan tentang kunci nada $\mathrm{F}(1 \mathrm{~b})$ dan nada $\mathrm{Bb}(2 \mathrm{~b})$, berbeda dalam musik KSF istilah Semol dan Dua Mol ini merupakan penamaan untuk judul lagu.

KSF merupakan salah satu jenis irama keroncong yang khas terdapat di Belitung. Hal ini dapat dilihat dari beberapa aspek yang terdapat dalam musik KSF sebagai berikut:

\section{Instrumen}

Sejak awal berkembangnya musik keruncong di pulau Mendanau memang hanya ada beberapa Instrumen yang digunakan dalam musik KSF berupa (1) Biola (Viul), (2) Gitar akustik, (3) Ukulele dan (4) Gitar Bas Akustik.

$$
\text { a. Biola ( Viul ) }
$$


Biola dalam permainan musik KSF berfungsi sebagai pemegang melodi lagu, biola ini bertalikan empat dengan stem nada dari bawah ke atas e-b-f\#-c\#. Hal ini terjadi karena atas kenyamanan perasaan dari pemain biola

\section{b. Gitar Akustik}

Gitar dalam permainan musik KSF berfungsi sebagai pembawa melodi, namun terkadang juga sebagai pengiring, dalam permainan KSF juga menggunakan enam senar dengan stem nada dari bawah ke atas e-a-c\#-f\#-b-d\#. Stem nada yang diturunkan pada senar E, senar G dan senar D. Hal ini juga terjadi karena menyesuaikan dengan instrumen yang lain dan juga untuk memudahkan memainkan pola melodi saat bermain lagu KSF (Wawancara dengan Ahmad Bin Bujang Tanggal 6 November 2017).

\section{c. Ukulele}

Ukulele dalam musik KSF sebagai pemegang ritmis dari pada lagu yang dimainkan. Ukulele dalam KSF Pengekar Campo juga dibuat secara mandiri oleh Kik Mad dengan menggunakan pohon nangka, tali pancing yang digunakan untuk memancing ikan digunakan sebagai senar ukulele dan stem nada yang digunakan KSF b-e-g\#-c\#. Secara teknik perminan yaitu dipetik secara bersamaan dengan nada akord yang sama hanya saja berbeda secara ritmis.

\section{d. Gitar Bas Akustik}

Bas tergolong alat musik dawai yang memiliki kesamaan dengan gitar akustik kemudian dimainkan dengan cara dipetik. Stem nada yang digunakan tetap yaitu e-a-d-g pada senar bawah hingga atas. Gitar bas dalam permainan KSF berfungsi sebagai pengendali ritmis.

\section{Tangga Nada}

Tangga nada dalam musik Barat menggunakan tangga nada diatonis baik mayor maupun minor. Masyarakat Melayu Belitung menggunakan tangga nada diatonis, maka musik KSF dapat dikatakan sebagai musik yang menggunakan tangga nada diatonis, hal ini dapat dijelaskan dari instrumen yang digunakan berupa berasal dari Barat. Penjelasan lain dapat juga dibuktikan dari stem nada seperti contoh dalam lagu Semol, nada yang digunakan berupa nada 4\# atau E= do, nada e didapat dari stem nada pada instrumen. 


\section{Bentuk Lagu}

Pada musik KSF terdapat dua lagu yang sering dimainkan yaitu semol dan dua mol. Kedua lagu ini ialah sebuah bentuk melodi khusus hanya dimainkan dalam musik KSF yang dimainkan secara berulang-ulang mengikuti pantun yang dinyanyikan, untuk mengetahui bentuk dari kedua lagu tersebut akan dijelaskan sebagai berikut:

\section{a. Bentuk Lagu KSF Semol}

Jumlah birama yang terdapat KSF Semol berjumlah 20 birama, tidak termasuk intro dan coda, dengan sukat 4/4, kemudian bentuk kalimat pada satu pantun yang terdapat pada lagu A - A1 - A2, permainannya selalu dimulai dengan intro yang dimainkan oleh gitar akustik berupa improvisasi dengan peralihan dari akor Tonika ke akord Dominan atau dari akord I ke akord V. Pembawaan syair pantun dilakukan secara improvisatoris.Pada lagu KSF Semol pengulangan birama terjadi menyesuaikan pada pantun yang dinyayikan.

\section{b. Bentuk Lagu KSF Dua Mol}

Jumlah birama yang terdapat pada KSF Dua Mol berjumlah 18 birama, tidak termasuk intro dan coda, dengan sukat 4/4 kemudian bentuk kalimat yang terdapat pada satu pantun pada lagu A - A1 - A2 - A2 - A, permainannya selalu dimulai dengan intro permainan gitar akustik berupa improvisasi dengan peralihan akord dari akord I atau Tonika ke akord V atau Dominan. Pembawaan syair pantun dilakukan secara improvisatoris. Pada KSF Dua Mol sama dengan KSF Semol yaitu terjadi pengulangan pola melodi yang mengikiti pantun.

\section{Harmoni}

\section{a. KSF Semol}

Pada lagu KSF Semol dimainkan pada tangga nada E mayor, nada ini didapatkan pada akord nada pada instrumen ukulele dan bas yang membangun progresi akord I - IV - I - V, jika digambarkan skema progresi akord sebagai berikut: 
Introduksi

\begin{tabular}{|c|c|c|c|}
\hline I - - - & I - - - & I - - - & I - - - \\
\hline IV - - - & IV - - - & IV - - - & IV - - - \\
\hline IV - - - & I - - - & | I - - - & | I - - - \\
\hline I - - - & I - - - & I - - - & I - - - \\
\hline V - - - & V - - - & V - - - & V - - - \\
\hline
\end{tabular}

Pada skema progresi akord diatas itu pada satu putaran melodi lagu KSF Semol. Contoh potongan akord dalam pola ritmis ukulele Ngelingkapada KSF Semol.

Ukulele Ngelingka

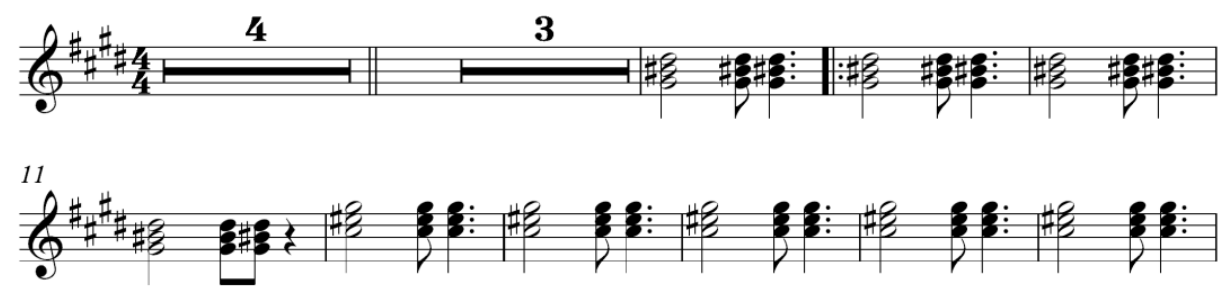

b. KSF Dua Mol

Pada lagu KSF Dua Mol dimainkan pada tangga nada A mayor, nada didapatkan pada akord nada pada instrumen ukulele dan bas yang membangun progresi akord yang sama dengan KSF Semol yaitu I - IV - I - V , jika digambarkan skema akord sebagai berikut.

\section{Introduksi}

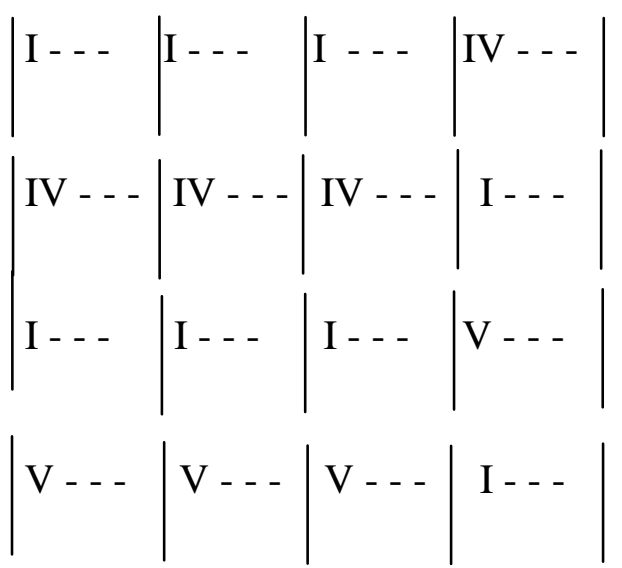




$$
\mid \text { I - - } \mid \text { I - - - }
$$

Contoh potongan akor dalam pola ritmis ukulele nganak pada KSF Dua Mol.

Ukulele Nganak

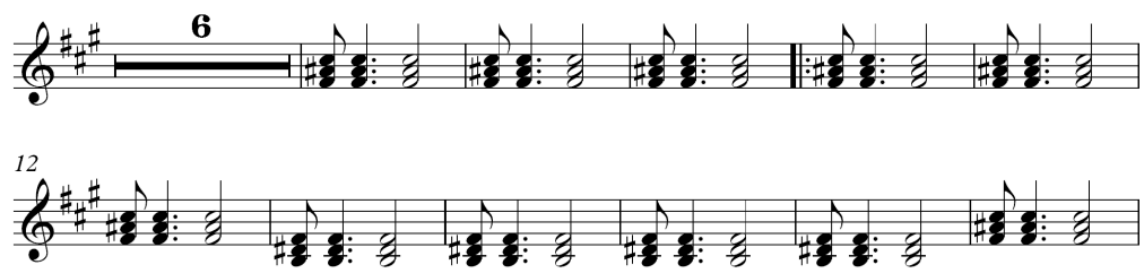

5. Ritme

Pada musik KSF terdapat jenis instrumen yang berperan memberikan ritme atau instrumen yang berfungsi sebagai pengiring dan pemegang ritmis. Teknik permainan dengan cara di petik atau di genjreng dari senar bawah ke senar atas kemudian dari senar atas ke bawah terus seperti itu berulang-ulang.Pada ukulele terdapat tiga ukulele yang memiliki pola ritmis yang dikenal dengan istilah Ngelingka atau pola A, Nyakar atau pola B, dan Nganak atau pola C. Pada bas hanya ada satu pola ritmis yang terdapat dalam permainan KSF. Demikian gambar dari pola ritmis pada ketiga ukulele dan bas.

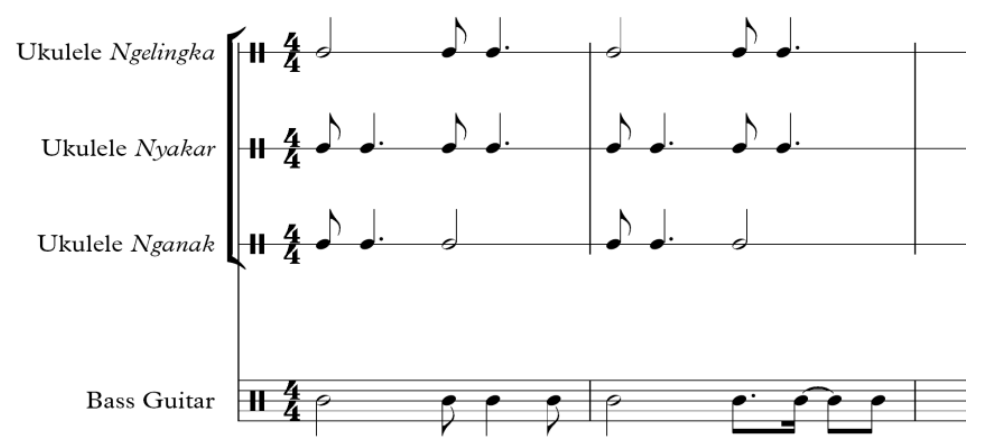

6. Pembawaan Vokal

Pada musik KSF vokal dinyayikan oleh dua orang yaitu laki-laki dan perempuan, liriknya berupa syair pantun,pembawaan vokal atau gaya vokalnya mengikuti gaya vokal dalam musik melayu yang sering disebut cengkok atau grenek, kemudian vokal dinyayikan dengan mendayu-dayu, gaya vokal setiap 
penyayi berbeda-beda, sehingga cengkok atau grenek tersebut dilakukan sesuai dengan improvisasi setiap penyayi.

\section{Analisis Motif Lagu}

Analisis dibutuhkan untuk dapat mengetahui secara utuh terwujudnya sebuah lagu. Pada analisis ini penulis memilih pola melodi dari permainan biola, hal ini dilakukan karena melodi biola merupakan melodi pokok dalam permainan musik KSF. Dalam proses analisis tersebut dibutuhkan alat untuk mengupasnya seperti (1) Pengulangan secara harafiah, (2) dipindah pada tingkat lain (sekuens naik/turun) (3) pembesaran interval (4) pemerkecilan interval (5) pembalikan (6) pembesaran nilai nadanya (7) pemerkecilan nilai nadanya (Karl Edmud Prier, 1996: 26-34).

Rangkaian melodi KSF Semol dibangun dari sebuah ide musikal yang terletak pada birama 10 - 14 dalam kalimat m a 1 sebagai motif pokok (tanya).

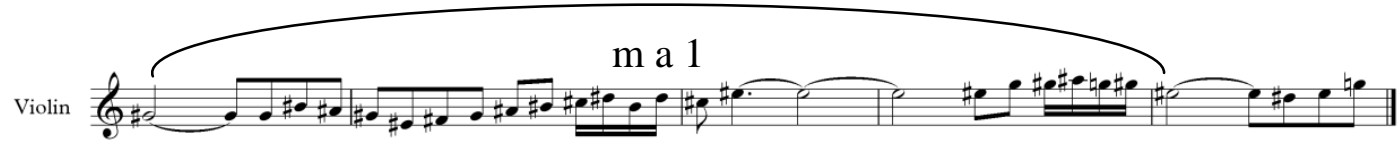

Dan selanjutnya pada birama 14 - 17 merupakan motif jawabnya, gabungan dari m a 1 dan m a 2 membentuk kalimat A 1 .

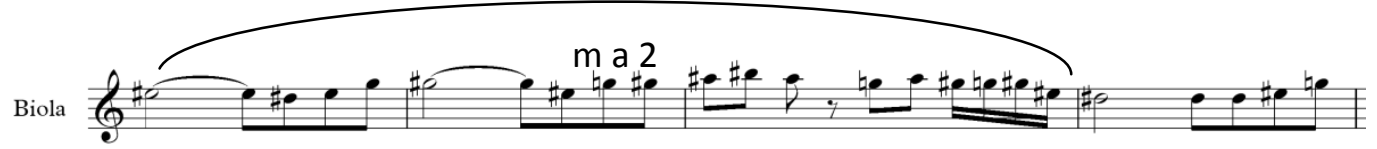

Uraian berikutnya adalalah kalimat A 2, motif pokok terletak pada birama 21 - 24 sebagai motif tanya A 2.

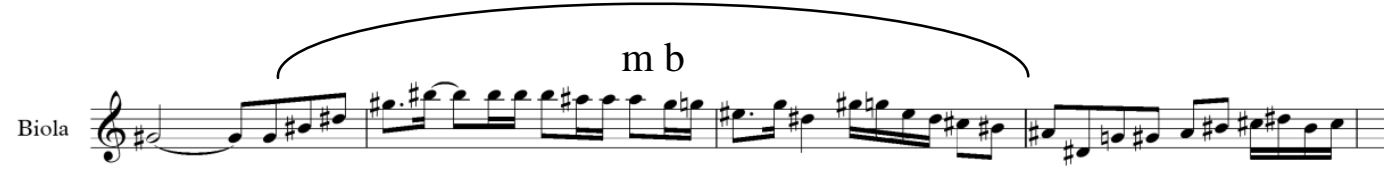

Dan selanjutnya pada birama 25 - 26 terjadi pengulangan naik atau sekuens naik berupa penegasan pada lirik lagu atau penegasan pada dari bar 24. 


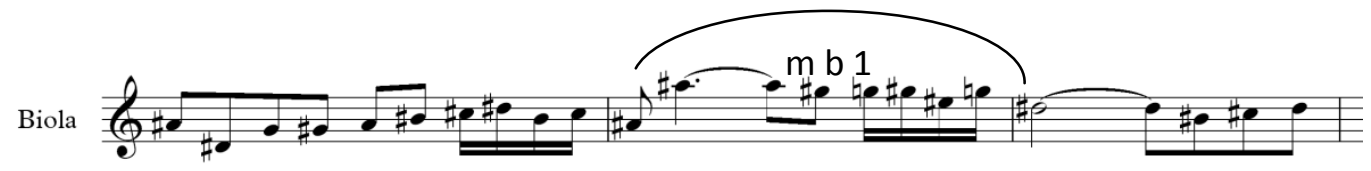

kemudian pada bar 26 - 28 terdapat motif jawab pada kalimat A 2.

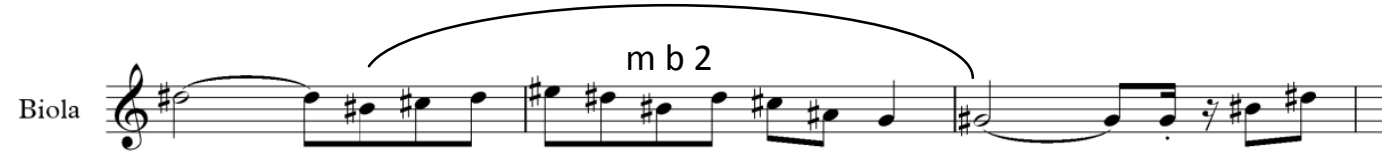

Uraian di atas terdapat kalimat tanya atau "m b" pada bar $21-24$, pengulangan sekuens naik atau "m b 1" pada bar $25-26$ berupa penegasan dari bar 24, kemudian pada "m b 2" yaitu bar ke 26 - 28 merupakan motif jawab dalam kalimat A 2. Maka dari itu penggabungan kaliamat A 1 dengan kalimat A 2 membentuk sebuah kalimat A (tanya) jika dilihat dari lirik pantun terdapat pada kalimat sampiran pada pantun, hal ini terjadi karena secara permainan melodi hanya ada 20 bar sehingga untuk menyampaikan kalimat jawaban dari pantun. Perlu dijelaskan bahwa Kalimat B atau pola melodi jawaban dari pantun merupakan pengulangan melodi pada kalimat A (tanya).

\section{Tinjauan Fungsi Musik KSF dalam Acara Selamat Laut}

Musik KSF merupakan sebuah kesenian yang selalu bersentuhan dalam berbagai aktivitas budaya masyarakat. Hal ini dapat dilihat pada kegiatan upacara Selamat Laut yang menjadi bukti bahwa kesenian ini masih sering dipentaskan pada setiap kegiatan masyarakat, walau hanya ditempatkan sebagai hiburan untuk masyarakat yang sedang makan pada saat upacara Selamat Laut tersebut. Berpijak dari penjabaran fungsi seni pertunjukan, R.M Soedarsono membaginya menjadi fungsi primer dan fungsi sekunder.

\section{Fungsi Primer Musik KSF}

a. Fungsi Sebagai Hiburan

Fungsi hiburan dapat dilihat dari penampilan sebuah pertunjukan yang pada saat pelaksanaannya dapat memberikan suasana yang berbeda pada sebuah 
sajian pertunjukan sehingga menimbulkan antusias pada masyarakat untuk menyaksikan pertunjukan tersebut.Musik KSF dimasukan dalam rangkaian upacara untuk menghibur para penonton dan tamu yang hadir pada upacara Selamat Laut saat menikmati makanan, sehingga nuansa makan bercampur dalam alunan melodi dari musik memanjakan para penonton yang sedang menikmati makanan.

\section{a. Fungsi Presentasi Estetis}

Fungsi presentasi estetis ialah bagaimana sebuah pertunjukan disajikan atau dipertontonkan kepada penonton sehingga dapat dilihat sebagai sebuah sajian yang menarik dengan nilai-nilai keindahan yang ada dalam pertunjukan tersebut. Disajikan dalam bentuk yang mengandung kualitas keindahan, berupa adanya keteraturan, struktur, kosmos di dalam wujudnya.

\section{Fungsi Sekunder Musik KSF}

a. Fungsi sebagai Peningkat Solidaritas Masyarakat

Musik KSF berkembang dan hidup dalam lingkungan masyarakat desa Suak Gual yang ada di pulau Mendanau sehingga pelaku dari musik KSF secara keseluruhan berasal dari desa Suak Gual yang berkerja sebagai nelayan dan petani ladang. Sehingga untuk menghibur dan membangun silaturahmi menjalin hubungan melalui musik KSF secara pelaku atau penikmat dari musik ini.

\section{b. Fungsi sebagai Media Komunikasi}

Musik KSF sebagai sebuah musik ansembel yang mampu menarik perhatian pendengarnya melalu lirik pantun yang tersampaikan dalam musik tersebut. Penonjolan utama dari musik KSF ialah pada lirik pantun. Ketika masyarakat mendengarkan pantun dari musik KSF yang terkadang menimbulkan respon untuk masyarakat membalas maksud pantun tersebut, seperti pengucapan salam yang terdapat pada lirik pastinya terjadi hubungan timbal balik dengan menjawab ucapan salam tersebut.

\section{Kesimpulan}

Aktivitas upacara Selamat Laut yang dilakukan secara terbuka bukanlah tidak memiliki sebuah maksud, acara yang dipersiapkan memang terjadi karena 
adanya tuntutan dari alam serta sebuah peristiwa yang hanya dilakukan setiap setahun sekali. Proses penyajiannya melalui persiapan yang dilakukan selama lima hari dengan menyajikan berbagai seni pertunjukan serta perlombaan. Puncak dari acara ialah proses upacara Selamat Laut yang diikuti oleh seluruh masyarakat nelayan dengan dipimpin oleh dukun kampung dengan melakukan doa bersama sebagai sebuah permohonan kepada Sang Pencipta atau Tuhan. Kemudian dengan proses akhirnya berupa pemercikan air Tepung Tawar yang bermakna untuk menawar hal-hal buruk yang dapat terjadi selama beraktivitas dilaut.

Pada puncak perayaan ini lah musik KSF ditempatkan dalam rangkaian acara dengan penyajian musik dan pantun, pada saat acara makan bersama dalam upacara Selamat Laut. Musik KSF akhirnya merupakan sebuah musik yang berbeda dengan musik Keroncong pada umumnya, musik KSF hanya mengadopsi instrumen ukulele dengan menambah jumlah ukulele yang digunakan dalam permainannya menjadi tiga, kemudian musik KSF memiliki dua bentuk melodi yaitu Semol dengan 20 birama dan Dua Mol dengan 18 birama yang juga merupakan untuk menyebutkan judul lagu dalam musik KSF.

Melalui upacara Selamat Laut memberikan fungsi yang penting pada musik KSF yaitu sebagai fungsi primer, fungsi sebagai hiburan serta sarana presentasi estetis dan fungsi sekunder, fungsi sebagai peningkat solidaritas dan fungsi sebagai media komunikasi.

Melalui fungsi inilah menimbulkan rasa memiliki dari musik KSF yang kemudian akan tetap melekat pada identitas dari masyarakat pemiliknya, sehingga menempatkan musik KSF sebagai kesenian yang penting pada setiap perayaan yang dilakukan masyarakat. Karena musik KSF merupakan gambaran dari masyarakat pemiliknya.

\section{Daftar Pustaka}

Merriam,Alan P. 1964.The Anthopologi of Music. Chicago, Illinois: Northwestern University Press.

Nettl, Bruno. 1964.Theory and Method in Ethnomusicology.New York: The Free Press of Glencoe, A Division of the Malmlea Company. 
Harmunah. 1987. Musik Keroncong. Yogyakarta: Pusat Musik Liturgi.

Husin Abdullah,Husnail. 1983.Sejarah Perjuangan Kemerdekaan R.I. di BangkaBelitung. Jakarta: PT Karya Unipress.

Nakagawa,Shin. 2000.Musik dan Kosmos sebuah Pengantar Enomusikologi. Jakarta: Yayasan Obor Indonesia.

Sumarjo, Jakob.2000.Filsafat Seni. Bandung: Penerbit ITB.

Djamin, Syamsul, dkk. 2008.Kamus Terbaru Bahasa Indonesia. Surabaya:Reality Publisher.

SJ, Kard- Edmund Prier. 1996. Ilmu Bentuk Musik. Yogyakarta: Pusat Musik Liturgi.

Banoe,Pono. 2003.Pengantar Pengetahuan Harmoni. Yogyakarta: Kanisius.

Soedarsono, R.M. 2001. Metodelogi penelitian Seni Pertunjukan dan Seni Rupa. Bandung: Masyarakat Seni Pertunjukan Indonesia.

AHSoeharto, SoenardiAhmad, dan SunupratomoSamidi. 1996.Serba-Serbi Keroncong, Jakarta: Musika.

BramantyoTriyono. 2004.Desseminasi Musik Barat Di Timur, Yogyakarta: Yayasan Untuk Indonesia.

Erman Erwiza. 2009. Menguak Sejarah Timah Bangka Belitung, Yogyakarta: Ombak.

Ganap,Vicrorius. 2004. "Krontjong Toegoe Sejarah Kehadiran Komunitas dan Musiknya di Kampung Tugu, Cilincing Jakarta Utara”, Disertasi untuk memperoleh Derajat Doktor dalam ilmu budaya, Universitas Gajah Mada.

\section{Narasumber}

Suherman Jabing, Ketua grup Keroncong Stambul Fajar Pengekar Campo.

Ahmad Bin Bujang, sebagai Guru dan pemain Keruncong Stambul Fajar Pengekar Campo.

Solihin, sebagai Ketua Dukun Kampung desa Suak Gual.

Bahani, sebagai ketua adat yang ada di pulau Mendanau. 